Br Heart F 1985; 53: 167-72

\title{
Tetralogy of Fallot with major aortopulmonary collateral arteries
}

\author{
JAMES M RAMSAY, FERGUS J MACARTNEY, SHEILA G HAWORTH \\ From the Department of Paediatric Cardiology, The Hospital for Sick Children, London
}

SUMMARY The clinical features of eight patients with tetralogy of Fallot and major aortopulmonary collateral arteries were determined and found to be usually unhelpful in differentiating such patients from those with pulmonary atresia with ventricular septal defect. The point of connection between the pulmonary and collateral arteries could usually be demonstrated at cineangiography by observing washin and washout between the two systems. The central pulmonary arteries connected with the entire pulmonary vascular bed in the five patients in whom the anatomy of the pulmonary circulation was clearly demonstrated and were thought to do so in the remaining three patients also. In six out of eight patients only one collateral artery connected with each hilar pulmonary artery.

These findings suggest that the anatomy of the pulmonary circulation in patients with tetralogy of Fallot and major aortopulmonary collateral arteries is usually less complex than in pulmonary atresia with ventricular septal defect, making the outlook for complete repair more hopeful. The major determinant of successful complete repair appears to be pulmonary arterial size. Early palliative surgery to increase pulmonary blood flow is recommended to encourage normal growth of the central and intrapulmonary arteries.

Unlike in patients with pulmonary atresia and ventricular septal defect the association of tetralogy of Fallot with major aortopulmonary collateral arteries is rare. In pulmonary atresia with major aortopulmonary collateral arteries a successful intracardiac repair depends on the size of the central and intrapulmonary arteries, the absence of stenoses, and the number of lobar and segmental pulmonary arteries connected to the central pulmonary arteries. The anatomy of the pulmonary arterial circulation in patients with tetralogy of Fallot and major aortopulmonary collateral arteries has not been well documented. We therefore describe the clinical and angiographic features in eight such patients.

\section{Patients and methods}

Eight patients from this hospital and Killingbeck Hospital, Leeds, had cineangiographic demonstration of tetralogy of Fallot with a patent right ventricular

Requests for reprints to Professor F J Macartney, The Hospital for Sick Children, Great Ormond Street, London WCIN 3JH.

Accepted for publication 4 September 1984 outflow tract and major aortopulmonary collateral arteries. Patients with an acquired collateral circulation were excluded from the study. The earliest date of cardiac catheterisation was 1972. Four patients came from each hospital; five were girls and three were boys.

Details of the clinical presentation, physical signs, cardiac catheterisation and angiographic studies, surgical treatment, and outcome were taken from the hospital records. The cineangiograms were carefully studied in order to delineate the blood supply of each bronchopulmonary segment of lung. The presence of washin and washout was specifically sought to help decide whether a segment of lung had a dual pulmonary blood supply. ${ }^{1}$ Several patients were studied at a time when selective injections into the major aortopulmonary collateral arteries consisted of a single large film exposure of a hand injection of contrast medium into the collateral artery. This made it difficult to determine segmental pulmonary arterial blood supply in some patients with absolute confidence.

The central pulmonary arteries and their branches and the collateral arteries and their branches were mapped out on a diagram of the bronchial branching pattern. ${ }^{2}$ The size of the pulmonary trunk and central 
and intrapulmonary arteries was assessed. The side of the aortic arch and other intracardiac and extracardiac abnormalities were recorded.

\section{CLINICAL PRESENTATION}

The patients presented at between 1 day and 3 years of age. None required urgent treatment, and there was no history of hypoxic spells either at presentation or later during follow up. Mild cyanosis and a murmur were noted in six babies during the first week of life. In one patient mild cyanosis, sweating, and tachypnoea on feeding were noted at 6 weeks. The remaining patient, the oldest in the series, born in 1942, did not present until 3 years of age when she was noted to be mildly cyanosed and short of breath.

Six patients had a prominent continuous murmur, of whom two also had a soft systolic murmur at the left sternal border. One patient had a loud systolic murmur with a thrill at the left sternal border and one only a soft systolic murmur. All had a single second heart sound. An ejection click was heard in three patients. The chest radiograph showed a right aortic arch in six patients. Pulmonary vascular markings were decreased in three, normal in three, and increased in the remaining two patients. In all cases, the electrocardiogram showed right axis deviation and signs of right ventricular hypertrophy. Cross sectional echocardiography was available for only the last two patients and appeared to show pulmonary atresia with ventricular septal defect.

The clinical diagnosis was pulmonary atresia with ventricular septal defect and major aortopulmonary collateral arteries in six patients. The remaining two patients were thought to have tetralogy of Fallot, one with acquired collateral circulation.

\section{CINEANGIOGRAPHY}

Four patients had selective cineangiograms into the major aortopulmonary collateral arteries. All these collaterals arose from the descending thoracic aorta. Table 1 shows their number and distribution. An injection into the right ventricular outflow tract was performed in three patients and an injection into the left pulmonary artery in one (Fig. 1). Injection at these sites combined with selective injections into the major aortopulmonary collateral arteries gave the best definition of the segmental pulmonary arterial blood supply. In those patients with selective cineangiograms it was relatively easy to decide whether or not the major aortopulmonary collateral arteries were in communication with the pulmonary arteries by looking for washin and washout (Fig. 2). This was more difficult in the remaining patients, but if the aortograms were studied carefully washout could sometimes be demonstrated. In five patients the major aortopulmonary collateral arteries were seen connecting with the hilar pulmonary arteries. In those cases the central pulmonary arteries appeared to supply $100 \%$ of the bronchopulmonary segments. One patient had an absent left central pulmonary artery, but the right pulmonary artery connected with all the segmental arteries of the right lung and was also perfused by one major aortopulmonary collateral artery which joined the right pulmonary artery at the hilium. In the other two patients it was not possible to be certain of the segmental pulmonary arterial blood supply, but there was a considerable amount of washout at the hilum of both lungs, suggesting that the central pulmonary arteries connected with all the bronchopulmonary segments in each lung.

The central pulmonary arteries were hypoplastic in six patients, and normal in the other two. The intrapulmonary arteries were also small in the six patients with hypoplastic central vessels. In one of the two patients with normal sized central pulmonary arteries, the intrapulmonary arteries of the left lung were smaller than normal (Fig. 1). The presence of a right aortic arch was confirmed in six of the eight patients.

SURGICAL OPERATIONS AND OUTCOME

Five patients (cases 1, 4, 5, 6, and 7) had an aor-

Table 1 Details of major aortopulmonary collateral arteries

\begin{tabular}{|c|c|c|c|c|c|}
\hline $\begin{array}{l}\text { Case } \\
\text { No }\end{array}$ & $\begin{array}{l}\text { Selective } \\
\text { cineangiograms* }\end{array}$ & $\begin{array}{l}\text { No and site } \\
\text { of collaterals }\end{array}$ & $\begin{array}{l}\text { Segments supplied } \\
\text { by } C P A\end{array}$ & Size of $C P A$ & Intrapulmonary arteries \\
\hline $\begin{array}{l}1 \\
2 \\
3 \\
4\end{array}$ & $\begin{array}{l}\text { Yes } \\
\text { No } \\
\text { Yes } \\
\text { No }\end{array}$ & $\begin{array}{l}\text { 2: } 1 \text { left, } 1 \text { right } \\
\text { 2: } 1 \text { left, } 1 \text { right } \\
\text { 3: } 2 \text { left, } 1 \text { right } \\
1 \text { right }\end{array}$ & $\begin{array}{l}100 \% \\
\text { Probably } 100 \% \\
100 \% \\
\text { Right lung } 100 \% \text {, } \\
\text { CLPA absent }\end{array}$ & $\begin{array}{l}\text { LPA 5-8 mm } \\
\text { Normal } \\
\text { 5-8 mm } \\
\text { RPA } 5-8 \mathrm{~mm}\end{array}$ & $\begin{array}{l}\text { RUL } 2-4 \mathrm{~mm} \\
\text { Normal } \\
2-4 \mathrm{~mm} \\
\text { HLPA fills late from bronchial } \\
\text { collaterals }\end{array}$ \\
\hline $\begin{array}{l}5 \\
6\end{array}$ & $\begin{array}{l}\text { Yes } \\
\text { No }\end{array}$ & $\begin{array}{l}\text { 2: } 1 \text { left, } 1 \text { right } \\
4 \text { or 5: } 2 \text { left, } \\
2 \text { or } 3 \text { right }\end{array}$ & $\begin{array}{l}100 \% \\
\text { Probably } 100 \%\end{array}$ & $\begin{array}{l}5-8 \mathrm{~mm} \\
5-8 \mathrm{~mm}\end{array}$ & $\begin{array}{l}\text { Not well defined but } 5-8 \mathrm{~mm} \\
\text { Not well defined but } 5-8 \mathrm{~mm}\end{array}$ \\
\hline $\begin{array}{l}7 \\
8\end{array}$ & $\begin{array}{l}\text { Yes } \\
\text { No }\end{array}$ & $\begin{array}{l}\text { 2: } 1 \text { left, } 1 \text { right } \\
\text { 4: } 3 \text { left, } 1 \text { right }\end{array}$ & $\begin{array}{l}100 \% \\
100 \%\end{array}$ & $\begin{array}{l}5-8 \mathrm{~mm} \\
\text { Normal }\end{array}$ & $\begin{array}{l}\text { Not well defined but } 5-8 \mathrm{~mm} \\
5-8 \mathrm{~mm} \text { on left, normal on right }\end{array}$ \\
\hline
\end{tabular}

CPA, central pulmonary artery; CLPA, central left pulmonary artery; LPA, left pulmonary artery; RPA, right pulmonary artery; RUL, right upper lobe; HLPA, hilar left pulmonary artery.

$\star$ Of major aortopulmonary collateral arteries. 

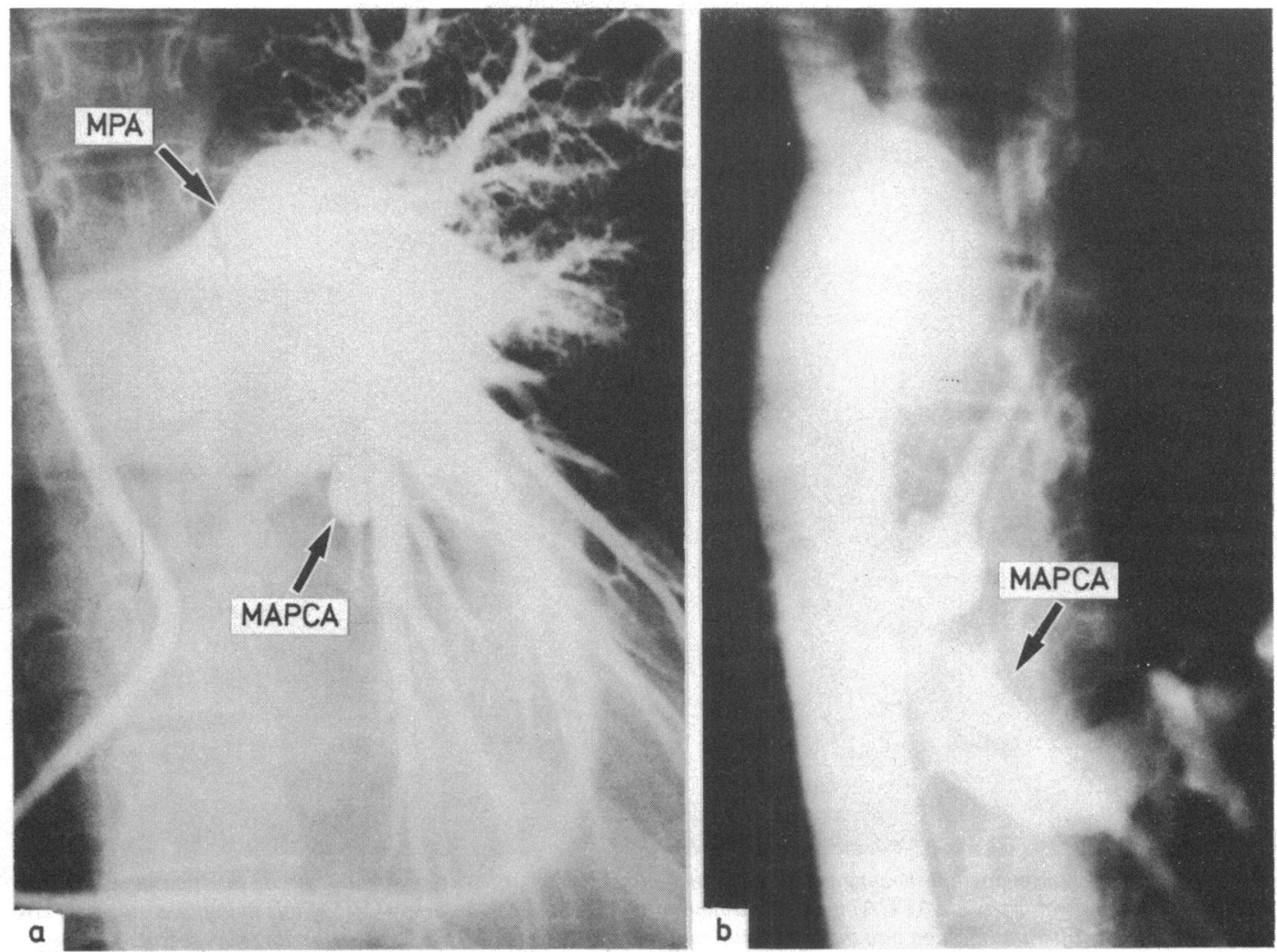

Fig. 1 Case 8: (a) Cineangiogram of the left pulmonary artery showing a good sized main pulmonary artery (MPA) and right pulmonary artery, but the left intrapulmonary arteries are smaller than normal. A major aortopulmonary collateral artery (MAPCA) can be seen to fill retrogradely. (b) An aortogram showing the major aortopulmonary collateral arteries supplying the left lung.

Table 2 Details of operation and outcome

\begin{tabular}{|c|c|c|c|c|c|}
\hline \multirow{2}{*}{$\begin{array}{l}\text { Sase } \\
\text { No }\end{array}$} & \multicolumn{2}{|c|}{ First operation } & \multicolumn{2}{|l|}{ Second operation } & \multirow[t]{2}{*}{ Outcome } \\
\hline & Age & Procedure & Age & Procedure & \\
\hline 1 & $71 / 2$ yrs & $\begin{array}{l}\text { Right BT shunt and ligation of } \\
\text { collaterals }\end{array}$ & $\begin{array}{l}2 \mathrm{~d} \text { after } \\
\text { first operation }\end{array}$ & Left modified BT shunt & Awaiting repair \\
\hline 2 & 13 yrs & $\begin{array}{l}\text { Ligation of collaterals, left } \\
\text { thoracotomy followed by complete } \\
\text { repair }\end{array}$ & & & $\begin{array}{l}\text { Well; residual pulmonary incompetence, } \\
\text { no postoperative cardiac } \\
\text { catheterisation }\end{array}$ \\
\hline 3 & 3 yrs & $\begin{array}{l}\text { Open infundibulectomy, pericardial } \\
\text { patch, no VSD closure }\end{array}$ & 5 yrs & $\begin{array}{l}\text { Closure of MAPCA using balloon } \\
\text { transaortically during cardiac } \\
\text { catheter }\end{array}$ & Follow up in USA since 1978 \\
\hline ; & $\begin{array}{l}11 \text { mnths } \\
2 \text { yrs }\end{array}$ & $\begin{array}{l}\text { Left BT shunt } \\
\text { Right BT shunt, collateral vessels } \\
\text { ligated }\end{array}$ & $31 / 2$ yrs & $\begin{array}{l}\text { Two collaterals tied via left } \\
\text { thoracotomy, then complete repair }\end{array}$ & $\begin{array}{l}\text { Awaiting repair } \\
\text { Died } 14 \text { hours postoperatively, } \\
\text { low output }\end{array}$ \\
\hline ; & 18 mnths & $\begin{array}{l}\text { MAPCA ligated, left BT shunt, } \\
\text { thrombosed-reoperation } 2 \text { days } \\
\text { later }\end{array}$ & 6 yrs & $\begin{array}{l}\text { Complete repair ( } 3 \text { hrs to dissect } \\
\text { Blalock) } \\
\text { Revision of left BT shunt }\end{array}$ & $\begin{array}{l}\text { Died } 12 \text { hours postoperatively, } \\
\text { low output } \\
\text { Awaiting repair }\end{array}$ \\
\hline 7 & 3 yrs & $\begin{array}{l}\text { Left BT shunt, ligation of } \\
\text { collaterals }\end{array}$ & 8 yrs & Complete repair, infundibular & Postoperative catheterisation, pulmonary \\
\hline B & 30 yrs & Left collaterals ligated & $31 \mathrm{yrs}$ & $\begin{array}{l}\text { resection, no pulmonary } \\
\text { valvotomy }\end{array}$ & $\begin{array}{l}\text { artery pressure } 42 / 6 \mathrm{~mm} \mathrm{Hg} \text {, right } \\
\text { ventricular pressure } 68 / 9 \mathrm{~mm} \mathrm{Hg} \text {, } \\
\text { residual right MAPCA }\end{array}$ \\
\hline
\end{tabular}

3T, Blalock-Taussig; MAPCA, major aortopulmonary collateral arteries; VSD, ventricular septal defect. 


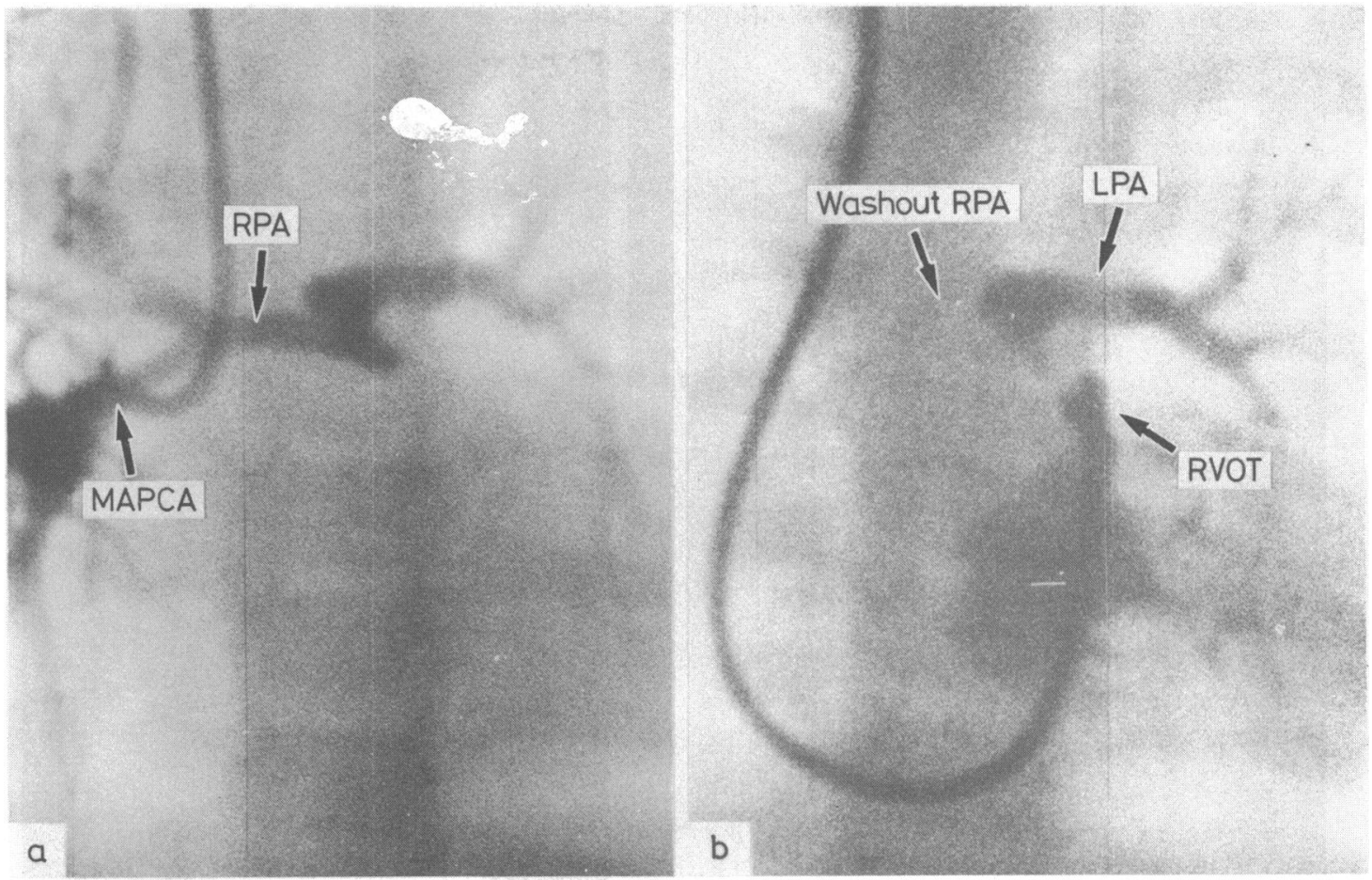

Fig. 2 Case 5: (a) Cineangiogram showing the filling of the central pulmonary arteries from a selective injection into a major aortopulmonary collateral artery (MAPCA) and (b) washout of the right pulmonary artery (RPA) due to major aortopulmonary collateral artery flow after an injection into the right ventricular ouffow tract (RVOT). LPA, left pulmonary artery.

topulmonary shunt performed (Table 2). None showed appreciable clinical improvement, and in three patients (cases 5,6 , and 7 ) subsequent cardiac catheterisation did not demonstrate a significant increase in the size of the pulmonary arteries. Collateral arteries were ligated in six patients, at the time of a shunt operation in four. There was no evidence of pulmonary infarction after ligation of a collateral artery in any patient. To date only two patients (cases 2 and 8) have survived a complete repair at the age of 13 and 30 years. These were the only patients with good sized pulmonary arteries. In both these patients the major aortopulmonary collateral arteries were tied, in one some months before the repair and in the other at the time of the repair. Two other patients (cases 5 and 6) died immediately after a complete repair. At necropsy the central pulmonary arteries were small. Both of these patients had previously had a Blalock-Taussig shunt. Three patients had palliative aortopulmonary shunts performed because their pulmonary arteries were small (they will be reinvestigated before an intracardiac repair is considered). The remaining patient (case 3) had an open infundibulec- tomy with pericardial patch insertion into the right ventricular outflow tract but without closure of the ventricular septal defect. This patient also had balloon occlusion of major aortopulmonary collateral arteries at a subsequent cardiac catheterisation in another institution. $^{3}$

\section{Discussion}

This is the first report of a group of patients with tetralogy of Fallot and major aortopulmonary collateral arteries. There have previously been two single case reports describing the association with limited clinical detail and no follow up. ${ }^{34}$

The findings in the present study suggest that in contrast to what is seen in most patients with pulmonary atresia and ventricular septal defect, in patients with tetralogy of Fallot all the bronchopulmonary segments are connected to the central pulmonary arteries. Furthermore, the number of collateral arteries arising from the descending thoracic aorta was generally smaller in patients with tetralogy of Fallot than in most patients with pulmonary atresia with 
ventricular septal defect. In six out of eight cases of tetralogy of Fallot usually only one collateral artery connected with each hilar pulmonary artery. Lastly, since major aortopulmonary collateral arteries are commonly associated with pulmonary atresia with ventricular septal defect, the presence of these collaterals might have been expected to occur only in cases with severe tetralogy of Fallot. In the present study, however, two patients had a relatively mild form of tetralogy of Fallot.

When the patients presented, a significant systolic murmur was often not heard despite the presence of an open right ventricular outflow tract, suggesting a low blood flow across the pulmonary valve. In patients thought to have pulmonary atresia with ventricular septal defect, therefore, it is important to determine whether or not the valve is in fact atretic by selective injection of contrast medium into the right ventricular outflow tract. Non-invasive investigations are not yet helpful in this respect, since it is difficult to distinguish an imperforate pulmonary valve from one that is barely patent by cross sectional echocardiography, at least in our experience. Nevertheless, the introduction of Doppler echocardiography with duplex scanning may make it possible to detect the presence of forward flow across the pulmonary valve. Improvement of near field resolution on cross sectional echocardiography should also help clarify the anatomy of the right ventricular outflow tract. Cineangiography will still be required, however, for demonstrating the pulmonary arterial anatomy and blood supply.

As in pulmonary atresia with ventricular septal defect selective injection into each major aortopulmonary collateral artery is mandatory to determine the source of blood supply. The size of the central and intrapulmonary arteries may be better demonstrated by right ventricular outflow tract or pulmonary arterial injection. In the present series each lung studied appeared to be entirely connected to the central pulmonary artery, but this is a small series. Investigation of these patients with tetralogy of Fallot should therefore aim to exclude the presence of collateral arteries connecting end to end with lobar or segmental pulmonary arteries that do not have an alternative source of blood supply. The investigations should also exclude the presence of a dual blood supply to a part of the lung by two or more collaterals, in addition to the supply from the right ventricular outflow tract.

As is the case in pulmonary atresia with ventricular septal defect, when all or most bronchopulmonary segmental arteries connect to the central pulmonary arteries, a successful intracardiac repair depends on the size of the central and intrapulmonary arteries. The only two patients in the present series to have had a successful repair were those with normal sized pul- monary arteries. Palliative surgery should aim at encouraging normal growth of the pulmonary arteries. The choice is between an aortopulmonary shunt and reconstruction of the right ventricular outflow tract. There is some uncertainty about which procedure is the more effective, particularly as it is not known whether the results in patients with pulmonary atresia can be extrapolated to those with a patent right ventricular outflow tract. The timing is, however, probably at least as important as the type of palliative surgery. Early palliative surgery is recommended since it is more likely to achieve growth rather than mere distension of the central and intrapulmonary arteries. Recent studies have shown that not only small but large central pulmonary arteries can be associated with hypoplastic intrapulmonary arteries in patients with tetralogy of Fallot without collaterals and with either pulmonary atresia or tetralogy of Fallot and major aortopulmonary collateral arteries. 56

In the future the management of patients with tetralogy of Fallot and major aortopulmonary collateral arteries may be modified by using transcatheter embolisation of the collateral arteries when the flow through the pulmonary valve is satisfactory, for example with detachable balloons. ${ }^{3}$ In this way, a lateral thoracotomy might be avoided in patients destined for a complete repair. In patients who require palliative surgery the major aortopulmonary collateral arteries could be embolised at cardiac catheterisation after the surgical procedure if the central pulmonary artery supplied most or all of each lung and pulmonary blood flow was adequate. This approach has the advantage that a preliminary trial occlusion of the collateral artery is possible, ${ }^{7}$ while monitoring systemic arterial saturation and watching for any other possible complications of collateral occlusion.

In conclusion, patients with tetralogy of Fallot and major aortopulmonary collateral arteries require a precise cineangiographic diagnosis and demonstration of the anatomy of the pulmonary circulation in order to plan the surgical management. Surgical treatment will have to be individualised, as in patients with pulmonary atresia and ventricular septal defect. Nevertheless, since the anatomy of the pulmonary circulation appears to be less complex in patients with tetralogy of Fallot than in those with pulmonary atresia and ventricular septal defect, management will usually consist of encouraging normal growth of the central and intrapulmonary arteries by increasing the pulmonary blood flow as a prelude to complete repair. The outlook may be more optimistic in patients with tetralogy of Fallot since they have an open right ventricular outflow tract and all or most bronchopulmonary segments appear to be connected to the central pulmonary arteries. 
We thank Dr Olive Scott warmly for her help in providing the information gathered some years ago at Killingbeck Hospital.

All authors were supported by the British Heart Foundation and FJM is also supported by the Vandervell Foundation.

\section{References}

1 Faller K, Haworth SG, Taylor JFN, Macartney FJ. Duplicate sources of pulmonary blood supply in pulmonary atresia with ventricular septal defect. $B r$ Heart f 1981; 46: 263-8.

2 Haworth SG, Macartney FJ. Growth and development of pulmonary circulation in pulmonary atresia with ventricular septal defect and major aortopulmonary collateral arteries. Br Heart $\mathcal{F}$ 1980; 44: 14-24.
3 Grinnell VS, Mehringer CM, Hieshima GB, Stanley P, Lurie PR. Transaortic occlusion of collateral arteries to the lung by detachable valved balloons in a patient with tetralogy of Fallot. Circulation 1982; 65: 1276-8.

4 Klint R, Hartmann A Jr, Schad N, Weldon C, Goldring $D$. Isolated lobular pulmonary artery atresia with systemic collaterals in tetralogy of Fallot. Chest 1972; 62: 512-4.

5 Johnson RJ, Haworth SG. Pulmonary vascular and alveolar development in tetralogy of Fallot: a recommendation for early correction. Thorax 1982; 37: 893-901.

6 Johnson RJ, Sauer U, Buhlmeyer K, Haworth SG. Hypoplasia of the intrapulmonary arteries in children with right ventricular outflow tract obstruction, ventricular septal defect, and major aortopulmonary collateral arteries. Pediatr Cardiol 1984; (in press).

7 Macartney FJ, Scott O, Deverall PB. Haemodynamic and anatomical characteristics of pulmonary blood supply in pulmonary atresia with ventricular septal defectincluding a case of persistent fifth aortic arch. Br Heart $\mathcal{f}$ 1974; 36: 1049-60. 